IJOPM

24,5

488

\title{
An examination of manufacturing organizations' performance evaluation
}

\section{Analysis, implications and a framework for future research}

\author{
Carlos F. Gomes \\ Faculdade de Economia da Universidade de Coimbra, Instituto de Sistemas e \\ Robótica, Coimbra, Portugal \\ Mahmoud M. Yasin \\ Department of Management and Marketing, East Tennessee State University, \\ Johnson City, Tennessee, USA, and \\ João V. Lisboa
}

Faculdade de Economia da Universidade de Coimbra, Instituto de Sistemas e Robótica, Coimbra, Portugal

Keywords Performance measurement (quality), Manufacturing industries, Decision making

Abstract The utilization of financial and non-financial measures in the evaluation of manufacturing organizations' performance is studied for a sample of 79 Portuguese financial analysts. Cluster analysis and multiple regression analysis are used to study the extent of use, importance and availability of information for 63 financial and non-financial measures. The results derived from this study point to the increasing importance of non-financial measures in the evaluation of manufacturing performance. Organizational and managerial implications of the findings are discussed, and a framework for future research is presented.

\section{Background}

The information revolution contributed significantly to enhancing both internal and external connectivity of business organizations. While the information age presented business organizations with valuable opportunities, it posed several challenges. These challenges are related to information security, sharability, availability, relevance and responsibility. Throughout their normal business practices, business organizations are called upon to share information with other organizations. In most cases, providing sensitive organizational performance related information is a necessity management would rather do without. However, such information may have to be reported to meet governmental regulations. In addition, performance-related information may have to be shared with financial institutions, such as banks and/or investment firms, in order to secure needed external funds. Financial and investment analysts of financial institutions utilize such information in their evaluation of organizations seeking external funds. In this context, understanding the dynamics surrounding the financial analysts' use of such information is very critical to the evaluated organizations.

This study attempts to shed some light on the nature of these dynamics. Specifically, International Journal of Operations $\&$ Production Management Vol. 24 No. 5, 2004 pp. $488-513$

(C) Emerald Group Publishing Limited 0144-3577

DOI 10.1108/01443570410532551 the study investigates the perceptions of financial analysts as to the utilization and relevance of both financial and non-financial performance measures in the context of 
manufacturing organizational performance evaluation. To achieve the objective of this study, the perceptions of 79 Portuguese financial analysts in relation to the extent of use, predictive value and availability of information for 63 measures are analysed. Insights gained from this research have both theoretical and practical values. Based on the results of this study, a conceptual research framework is advanced for future research.

\section{Relevant literature}

Before the 1980s, the organizational performance measurement process was characterized by a cost accounting orientation which emphasized selective financial indicators such as profit and return on investment. This approach received considerable criticisms due to focusing only on financial indicators. Critics argued that stressing on financial indicators only may lead to promoting short-term thinking (Banks and Wheelwright, 1979; Hayes and Garvin, 1982; Kaplan, 1983).

Johnson and Kaplan (1987) were among the first authors to criticize the traditional cost accounting-based approach organizational performance measurement. In the process, they underscored the need for an integrated performance measurement approach. They contended that the cost accounting approach focused on the minimization of variance rather than continuous improvement. In this context, McNair and Mosconi (1987) also called for the need for an integrated performance measurement approach. They stressed the need for the alignment of financial and non-financial measures in accordance with business strategy. Santori and Anderson (1987) underscored the importance of non-financial measures as tools to motivate personnel and measure their progress. They also outlined some of the key factors that should be considered when developing performance measures for the organization.

In the late 1980s, some frameworks which attempted to present a broader view of performance measurement started to appear in the literature (Cross and Lynch, 1988-1989; Khadem, 1988). Meanwhile, criticisms of the traditional performance measurement approach continued to mount. These criticisms are outlined below. They:

- encourage local optimization (Fry and Cox, 1989);

- are focused on the past (McNair et al., 1990);

- have been an impediment to implementation of just-in-time manufacturing strategies or the attainment of their potential benefits (Green et al., 1991; Hendricks, 1994; Najarian, 1993; Upton, 1998);

- do not provide adequate information for productivity measurement and improvement programs (Banker et al., 1989);

- they are lagged[1] performance indicators because they are historical in nature, by definition reporting on activities that have occurred already (Clinton and Hsu, 1997; Eccles and Pyburn, 1992; McNair et al., 1990);

- are the result of management action and organizational performance, and not the cause of it (Eccles and Pyburn, 1992; Hazell and Morrow, 1992);

- have failed to measure and integrate all the factors critical to the success of a business (Eccles, 1991);

- are not externally focused (Kaplan and Norton, 1992);

- are inappropriate in modern manufacturing settings (Drucker, 1990);
An examination of manufacturing organizations

489 
IJOPM

24,5

490

- say nothing about the factors, such as customer service innovation, the percent of first-time quality, and employee development, that actually help grow market share and profits (Birchard, 1995);

- lack the ability to guide the firm in its efforts to achieve manufacturing excellence (Wisner and Fawcett, 1991).

In response to these criticisms, a large number of performance measurement systems (PMSs) were proposed to broaden the performance measurement process. Among the most widely cited systems are the SMART (Cross and Lynch, 1988-1989; Lynch and Cross, 1991), the performance measurement matrix (Keegan et al., 1989), the balanced scorecard (Kaplan and Norton, 1992) and the integrated dynamic performance measurement system (Ghalayini et al., 1997).

Perhaps more focused on the intrinsic characteristic of each organization, some authors tended to stress the design and implementation aspects of a PMS than the general utility of a given PMS across organizations. These authors include, among others, Beamon (1999), Dixon et al. (1990), Eccles and Pyburn (1992), Flapper et al. (1996) and Neely et al. (1996). Their emphasis was more on promoting a case-by-case approach to PMS as opposed to uniform theory driven frameworks.

The performance measurement literature underscores some relevant guidelines for, and characteristics of, the integrated performance measurement systems, as summarized below:

- must reflect relevant non-financial information, based on key success factors of each business (Clarke, 1995);

- should be implemented as means of articulating strategy and monitoring business results (Grady, 1991);

- should be based on organisational objectives, critical success factors, and customer needs and should monitor both financial and non-financial aspects (Manoochehri, 1999);

- must accordingly change dynamically with the strategy (Bhimani, 1993);

- must meet the needs of specific situations in manufacturing operations and should be long-term oriented as well as simple to understand and implement (Santori and Anderson, 1987);

- must make a link to reward systems (Tsang et al., 1999); and

- financial and non-financial measures must be aligned and fit within a strategic framework (Drucker, 1990, McNair and Mosconi, 1987).

Examining the most recent literature, one finds words like balanced, integrated, linked, multi-faceted or multi-dimensional starting to be used to describe PMSs. However, words such as successful implementation, multi-implementation or repeatability are slow in forthcoming in the recent literature. The trend towards integrating financial and non-financial measures, coupled with the fact that more and more powerful enterprise resource planning systems are emerging, perhaps, may indicate that integrated PMSs are not out of reach. However, the road towards the modern integrated PMS is not without difficulties, due to the problems summarized below: 
- There are many non-financial measures that can be used by the organizations. The problem is which measures from the many available an organization should use (Medori and Steeple, 2000). Perhaps it all depends on the characteristics of the organization and the nature of its industry.

An examination of manufacturing organizations

- Problems with output measurability and timeliness of information (Noci, 1995).

- Little or no consideration is given for the existing measurement systems that companies may have in place (Medori and Steeple, 2000).

- They take a long time to implement (Noci, 1995).

With this literature review in mind, the objective of this study is to shed some light on the role and nature of financial and non-financial aspects of manufacturing performance as seen by financial analysts.

\section{Methodology}

Sample and procedure

The research instrument was sent to 298 financial analysts whose names and addresses were obtained from APAF, the Portuguese Association of Financial Analysts. As an incentive to participate in this study, the authors promised to make available a summary of the results. A total of 79 responses were received, resulting in a response rate of 26.51 percent.

To evaluate non-response bias, the authors requested the participants to send back the instrument, even if they chose not to participate in the study. They were also encouraged to send an e-mail explaining the reason for not completing the instrument; 39 letters and e-mails explaining the reasons for not completing the instrument were received. After adjusting the initial sample size, by removing 36 cases corresponding to the participants not currently engaged in financial analysis activities related to manufacturing organizations, the response rate became 30.15 percent. This response rate is considered high when compared with similar recent international studies reported in the literature research (Bhatt, 2000; Carr et al., 2000; De Toni and Tonchia, 2001; Najmi and Kehoe, 2001; Sohal et al., 2001)

The research instrument used in this study solicited biographical information on the respondents. Respondents were asked to provide information on their specialty and subspecialty, which company they worked for, and their job titles. The results obtained show that the majority of the respondents were generalists, who worked for banks and financial institutions. Almost 60 percent of these respondents tended to occupy high level positions in their firms (Table I).

\section{Instrument}

The research instrument used in this study is designed based on the work of Dempsey et al. (1997). The first phase of the instrument development included translation and adaptation to the reality of the Portuguese manufacturing sector. Thus, performance measures which were inconsistent with this reality were removed, while some more applicable measures were adapted from the literature and added to the instrument. In the second phase, the instrument was presented to a panel of experts, including both professionals and professors. Special attention was paid to using vocabulary consistent with the background of the participants. This objective was achieved after a few iterations. 
IJOPM

24,5

492

\begin{tabular}{lrr}
\hline Item & Frequency & Percentage \\
\hline Title/responsibilities & & \\
Director & 23 & 29.11 \\
Administrator & 15 & 18.99 \\
Manager & 5 & 6.33 \\
President & 4 & 5.06 \\
Consultant & 4 & 5.06 \\
Analyst of risk & 3 & 3.80 \\
Others & 21 & 26.58 \\
Did not answer & 4 & 5.06 \\
Total & 79 & 100.00 \\
Area of specialization & & \\
Generalist & 67 & 84.81 \\
Assets management & 2 & 2.53 \\
Finance markets & 2 & 2.53 \\
Did not answer & 8 & 10.13 \\
Total & 79 & 100.00 \\
Functional specialization & & \\
Financial analysis & 8 & 10.13 \\
Assets management & 4 & 5.06 \\
Credit management & 4 & 5.06 \\
Companies evaluation & 2 & 2.53 \\
Other & 34 & 43.04 \\
Did not answer & 27 & 34.18 \\
Total & 79 & 100.00 \\
Type of employing firm & & \\
Bank & 30 & 37.97 \\
Consultant & 9 & 11.39 \\
Financial institution & 6 & 7.59 \\
Broker/investment dealer & 3 & 3.80 \\
Freelancer & 2 & 2.53 \\
Other & 1 & 1.27 \\
Did not answer & & 100.00 \\
Total & &
\end{tabular}

The final version of the instrument is composed of 63 financial and non-financial measures, derived from the literature. These measures are organized in eight categories (adapted from Dempsey et al., 1997):
A. Financial
1. Earnings per share
2. Cash flow
3. Return on equity
4. Return on assets
5. Sales
6. EBIT\&EI $\div$ Sales[2]
7. Sales $\div$ total assets
8. Equity $\div$ total assets
9. Quality of accounting policies 
B. Product quality and customer satisfaction

10. Customer surveys

11. Warranty claims

12. Customer complaints

13. Percent of missed delay dates

14. Service responsiveness

15. Percent of returned orders

16. Litigations with customers

C. Process efficiency

17. Percent of products rejected by the quality control[3]

18. Product development time

19. Manufacturing cycle time

20. Order to delivery time

21. Ability to customize products

22. Operating costs per employee

23. Sales per employee

24. Cost of goods sold $\div$ inventory

25 . Accounts receivable $\div$ sales

26. Future investment needs

27. Actual production $\div$ planned production[3]

28. Age of plant and equipment

29. Percent of downtime on the production[3]

30. Capacity utilization

D. Product and process innovation

31. R\&D expenditures

32. Percent of products protected by patents

33. Number of new patents (last three years)

34. Number of new products (last three years)

35. Percent of sales due to new products

E. Competitive environment

36. Market share

37. Brand awareness

38. Potential for new competitors

39. Percent of sales from proprietary products

40. Strategic alliances

41. Litigation due to break of market competition rules

42. Geographic diversification

43. Customer diversification

44. Product diversification

F. Quality/independence of management

45. Continuity of management

46. Experience/reputation of management

47. Participation of shareholders on the firm's management

48. Independence of the management relative to the shareholders

49. Shareholder disputes

50. Dispersion of ownership

51. Ethical behavior of management
An examination of manufacturing organizations

493 
IJOPM

24,5

\section{4}

G. Human resource management

52. Equal employment opportunity

53. Employee involvement

54. Employee training

55. Profit share or other incentive plans

56. Insurance plans (life, health and education)

57. Employee turnover

58. Absentee rates

59. Safety record

60. Labor-management relations

H. Social responsibility

61. Environmental policies implemented

62. Community involvement

63. Litigation with the community

The selection of the eight categories is consistent with the feedback from the panel of experts. For each of the measures used, financial analysts were asked to indicate their responses in relation to the measure on 1-5 Likert-type scale.

Models, variables, and data analysis

The data obtained from the participants were analysed using cluster and regression analyses. The objective of the data analysis was to obtain a profile of the financial analysts in terms of their use of financial and non-financial measures in the performance evaluation of the performance of manufacturing organizations.

In the first phase, cluster analysis was used to evaluate responses. The frequency that financial analysts associated with each one of the 63 performance measures, their perceptions in terms of its predictive value, and finally their perceptions in terms of the ease of acquiring information for each measure were calculated.

The second phase of the data analysis utilized multiple regression analysis. The linear relationship tested is based on the variables included in the instrument, where the frequency of use (FU) of the performance measures is assumed to be a function of its predictive value (PV), and of the ease with which the information for the measure can be acquired (EA)

Thus, the model tested is:

$$
\mathrm{FU}=f(\mathrm{PV}, \mathrm{EA})
$$

The linear function to be estimated is:

$$
\overline{\mathrm{FU}_{i}}=\alpha_{0}+\alpha_{1} \overline{\mathrm{PV}_{i}}+\alpha_{2} \overline{\mathrm{EA}_{i}}+e_{i}
$$

where:

$\overline{\mathrm{FU}_{i}}=$ the mean frequency of use score on the $i$ th measure,

$\overline{\mathrm{PV}_{i}}=$ the mean predictive value score on the $i$ th measure,

$\overline{\mathrm{EA}_{i}}=$ the mean ease of acquisition score on the $i$ th measure,

$e_{i}=$ the variable that represents the residual,

$\alpha_{0}, \alpha_{1}$ and $\alpha_{2}=$ the linear parameters. 
The observation unit for this model is the average of the answers of all analysts for each measure. The use of regression analysis in this manner is consistent with Hair et al. (1998).

To gain insights into the relative use of the eight categories of information, a model which, in addition to the initial independent variables, also included binary variables representing each category of information was used. For the purpose of this model, the observation unit is the average of the answers of a particular respondent for each category of measures resulting in a maximum of $n \times 8$ observations. This model allowed for assessing the existence of interactions between the categories of information and the independent variables. The model used for this purpose is presented below:

$$
\overline{\mathrm{FUc}_{i}}=\beta_{0}+\beta_{1} \overline{\mathrm{VPc}_{i}}+\beta_{2} \overline{\mathrm{FAc}_{i}}+\sum_{j=1}^{7} \gamma_{j} D_{j}+\sum_{j=1}^{7} \delta_{j} D_{j} \overline{\mathrm{VPc}_{i}}+\sum_{j=1}^{7} \lambda_{j} D_{j} \overline{\mathrm{FAc}_{i}}+\mu_{i}
$$

where:

$\overline{\mathrm{FUc}_{i}}=$ the $i$ th respondent's mean frequency of use score for an information category,

$\overline{\mathrm{VPc}_{i}}=$ the $i$ th respondent's mean predictive value score for an information category,

$\overline{\mathrm{FAc}_{i}}=$ the $i$ th respondent's mean ease of acquisition score for an information on category,

$D_{j}=$ the binary variable with a value of 1 if the mean score is for category $j$ and 0 otherwise (the excluded category is the financial),

$D_{j} \overline{\mathrm{VPc}_{i}}=$ the interaction term between the predictive value and information category,

$D_{j} \overline{\mathrm{FAc}_{i}}=$ the interaction term between ease of acquisition and information category, $\mu_{i}$ is the residuals term,

$\beta_{0}, \beta_{1}, \beta_{2}, \gamma_{j}, \delta_{j}$ and $\lambda_{j}=$ the linear parameters.

Finally, the third phase of the data analysis utilized gap analysis to gain a better understanding of the relative importance of the non-financial measures as perceived by the financial analysts. The differences between the PV and the ease of acquisition for each of the 63 measures were examined. These differences were then multiplied by their PVs, as:

$$
\mathrm{GAP}_{i}=\left(\mathrm{PV}_{i}-\mathrm{EA}_{i}\right) \mathrm{PV}_{i}
$$

The differences were multiplied by their PVs to provide scores that reflect the relative importance of the PV on the measure utilization (Foster and Gupta, 1994). Thus, the larger this indicator is, the greater the disparity between the usefulness of the measure and its availability.

\section{Results}

\section{Cluster analysis results}

The results of the cluster analysis for each measure FU, PV and ease of acquiring information are reported in Tables II-IV. The first column in these tables represents the cluster number, the second column designates the measure, the third column designates the category to which the measure belongs, in the fourth column the
An examination of manufacturing organizations

495 
IJOPM

24,5

496

Table II.

Cluster analysis results relative to frequency of use measures
Cluster Measure

Standard Coefficient

Cat. Average deviation of variation

1

Cash flow

Return on equity

EBIT\&EI $\div$ sales

Sales

Market share

Future investment needs

Equity $\div$ total assets

Accounts receivable $\div$ sales

Experience/reputation of management

Product diversification

Brand awareness

Customer diversification

Return on assets

Continuity of management

Earnings per share

Dispersion of ownership

Sales $\div$ total assets

Potential for new competitors

3 Geographic diversification

Capacity utilization

Employee training

Strategic alliances

Cost of goods sold $\div$ inventory

Participation of shareholders on the firm's

management

Independence of the management relative to the

shareholders

Quality of accounting policies

Sales per employee

Ethical behavior of management

R\&D expenditures

Age of plant and equipment

Percent of sales due to new products

Operating costs per employee

Profit share or other incentive plans

Median

Percent of sales from proprietary products

Shareholder disputes

Number of new products (last three years)

Manufacturing cycle time

4 Absentee rates

Employee turnover

Environmental policies implemented

Employee involvement

Actual production $\div$ planned production

Labor-management relations

Litigation with the community

Insurance plans (life, health and education)

$\begin{array}{cccc}\text { A2 } & 4.56 & 0.80 & 0.18 \\ \text { A3 } & 4.32 & 0.87 & 0.20 \\ \text { A6 } & 4.31 & 0.81 & 0.19 \\ \text { A5 } & 4.29 & 0.93 & 0.22 \\ \text { E36 } & 4.19 & 0.92 & 0.22 \\ \text { C26 } & 4.04 & 1.03 & 0.25 \\ \text { A8 } & 4.01 & 1.08 & 0.27 \\ \text { C25 } & 4.01 & 0.91 & 0.23 \\ \text { F46 } & 3.99 & 1.04 & 0.26 \\ \text { E44 } & 3.92 & 0.92 & 0.23 \\ \text { E37 } & 3.90 & 1.02 & 0.26 \\ \text { E43 } & 3.89 & 1.03 & 0.26 \\ \text { A4 } & 3.86 & 1.05 & 0.27 \\ \text { F45 } & 3.76 & 1.13 & 0.30 \\ \text { A1 } & 3.72 & 1.36 & 0.37 \\ \text { F50 } & 3.70 & 1.15 & 0.31 \\ \text { A7 } & 3.69 & 1.07 & 0.29 \\ \text { E38 } & 3.63 & 1.21 & 0.33 \\ \text { E42 } & 3.60 & 1.21 & 0.34 \\ \text { C30 } & 3.58 & 1.09 & 0.30 \\ \text { G54 } & 3.58 & 1.05 & 0.29 \\ \text { E40 } & 3.57 & 1.12 & 0.31 \\ \text { C24 } & 3.56 & 1.22 & 0.34 \\ & & & \\ \text { F47 } & 3.51 & 1.13 & 0.32 \\ & & & \\ \text { F48 } & 3.51 & 1.32 & 0.38 \\ \text { A9 } & 3.49 & 1.26 & 0.36 \\ \text { C23 } & 3.41 & 1.17 & 0.34 \\ \text { F51 } & 3.41 & 1.26 & 0.37 \\ \text { D31 } & 3.36 & 1.13 & 0.34 \\ \text { C28 } & 3.35 & 1.11 & 0.33 \\ \text { D35 } & 3.35 & 1.18 & 0.35 \\ \text { C22 } & 3.29 & 1.26 & 0.38 \\ \text { G55 } & 3.29 & 1.16 & 0.35 \\ & 3.29 & & \\ \text { E39 } & 3.27 & 1.24 & 0.38 \\ \text { F49 } & 3.16 & 1.43 & 0.45 \\ \text { D34 } & 3.14 & 1.19 & 0.38 \\ \text { C19 } & 3.09 & 1.22 & 0.39 \\ \text { G58 } & 3.04 & 1.31 & 0.43 \\ \text { G57 } & 2.99 & 1.27 & 0.42 \\ \text { H61 } & 2.96 & 1.16 & 0.39 \\ \text { G53 } & 2.92 & 1.22 & 0.42 \\ \text { C27 } & 2.90 & 1.35 & 0.47 \\ \text { G60 } & 2.82 & 1.29 & 0.46 \\ \text { H63 } & 2.75 & 1.21 & 0.44 \\ \text { G56 } & 2.72 & 1.19 & 0.44 \\ & & & (\text { continued) } \\ & & & \end{array}$


Standard Coefficient

Cluster Measure

Cat. Average
Percent of products protected by patents

Percent of downtime on the production

Litigation due to break of market competition rules

Litigation with customers

Community involvement

Ability to customize products

Order to delivery time

Safety record

5

Service responsiveness

Product development time

Percent of products rejected by the quality control

Number of new patents (last three years)

Percent of returned orders

Percent of missed delay dates

Customer complaints

Customer surveys

Equal employment opportunity

Warranty claims

D32 2.70

C29 2.68

E41

B16 2.67

H62 2.67

C21 2.65

C20 2.63

G59 2.58

B14 2.55

C18 2.53

C17 2.51

D33 2.48

$\mathrm{B} 15 \quad 2.38$

$\mathrm{B} 13 \quad 2.35$

B12 2.30

B10 2.29

G52 2.28

B11 2.17
1.21

1.15

1.22

1.11

1.19

1.22

1.28

1.24

1.14

1.19

1.40

1.15

1.22

1.24

1.17

1.20

1.31

1.19
0.45

0.43

0.46

0.42

0.45

0.46

0.49

0.48

0.45

0.47

0.56

0.46

0.51

0.53

0.51

0.52

0.57

0.55

Note: Clusters were predefined to five to provide an analogy with the scale used on the questionnaire

Table II.

average of the financial analysts responses is reported, followed by the standard deviation, and the final column reports the coefficient of variation.

The FU results in Table II for the different measures are interesting. Four out of the five measures most used by the financial analysts in cluster 1 are financial in nature. This finding confirms the authors' expectations and it is consistent with the literature reviewed. On the other hand, the remaining financial measures are found in the second cluster mixed with non-financial measures.

In this context, it is not surprising to find all the traditional financial measures (category A) in the most used clusters. However, the fact that the first cluster also includes non-financial measures from category $\mathrm{E}$ (competitive environment), coupled with the fact that 10 out of the 18 most used measures (clusters 1 and 2) are non-financial measures is an interesting finding. It is also noted that clusters 1 and 2 , which include the most used measures, consist of eight measures which are financial in nature, two process efficiency related, five competitive environment related, and three quality/independence of management related.

Based on the results in Table II, cluster 5, which includes the least used measures, consists of six measures from category B (product quality and customer satisfaction), two measures from category $\mathrm{C}$ (process efficiency), one measure from category $\mathrm{D}$ (product and process innovation), and one measure from category $\mathrm{G}$ (human resources management). One would expect the measures in this cluster, especially measures from category $\mathrm{G}$, to be more used than was the case.

The cluster analysis results related to the financial analysts' perceptions of the PV of each of the 63 measures are presented in Table III. In Table III, the first cluster has only two measures from category A. Also, the second cluster includes only two 
IJOPM

24,5

498

2

Table III.

Cluster analysis results relative to measures PV
3 Return on assets

Standard Coefficient

Cluster Measure

Cat. Average deviation of variation

1 Future investment needs

Cash flow

Market share

EBIT \& EI $\div$ sales

Experience/reputation of management

Brand awareness

Potential for new competitors

Employee training

Customer diversification

Product diversification

Continuity of management

Sales

Percent of sales due to new products

Return on equity

Strategic alliances

Capacity utilization

Accounts receivable $\div$ sales

Age of plant and equipment

R\&D expenditures

Profit share or other incentive plans

Number of new products (last three years)

Independence of the management relative to the

shareholders

Ethical behavior of management

Operating costs per employee

Customer surveys

Geographic diversification

Service responsiveness

Equity $\div$ total assets

Shareholder disputes

Participation of shareholders on the firm's

management

Sales per employee

Median

Actual production $\div$ planned production

Sales $\div$ total assets

Labor-management relations

Dispersion of ownership

Employee involvement

Percent of missed delay dates

Absentee rates

Customer complaints

Quality of accounting policies

Percent of returned orders

Cost of goods sold $\div$ inventory

Percent of products protected by patents

Environmental policies implemented

Ability to customize products

$\begin{array}{cccc}\text { C26 } & 4.01 & 0.87 & 0.22 \\ \text { A2 } & 4.00 & 0.97 & 0.24 \\ \text { E36 } & 4.00 & 0.85 & 0.21 \\ \text { A6 } & 3.97 & 0.82 & 0.21 \\ \text { F46 } & 3.95 & 0.96 & 0.24 \\ \text { E37 } & 3.91 & 0.87 & 0.22 \\ \text { E38 } & 3.84 & 0.91 & 0.24 \\ \text { G54 } & 3.84 & 0.98 & 0.26 \\ \text { E43 } & 3.81 & 0.96 & 0.25 \\ \text { E44 } & 3.78 & 1.00 & 0.26 \\ \text { F45 } & 3.77 & 0.94 & 0.25 \\ \text { A5 } & 3.71 & 1.01 & 0.27 \\ \text { D35 } & 3.70 & 0.92 & 0.25 \\ \text { A3 } & 3.66 & 0.90 & 0.25 \\ \text { E40 } & 3.63 & 0.96 & 0.26 \\ \text { C30 } & 3.62 & 0.95 & 0.26 \\ \text { C25 } & 3.57 & 0.92 & 0.26 \\ \text { C28 } & 3.56 & 0.96 & 0.27 \\ \text { D31 } & 3.56 & 0.88 & 0.25 \\ \text { G55 } & 3.53 & 1.00 & 0.28 \\ \text { D34 } & 3.49 & 0.91 & 0.26 \\ \text { F4 } & 3.47 & 1.17 & 0.34 \\ \text { A4 } & 3.42 & 1.00 & 0.29 \\ \text { F51 } & 3.42 & 1.08 & 0.32 \\ \text { C22 } & 3.40 & 0.90 & 0.26 \\ \text { B10 } & 3.39 & 1.07 & 0.32 \\ \text { E42 } & 3.39 & 1.02 & 0.30 \\ \text { B14 } & 3.36 & 1.12 & 0.33 \\ \text { A8 } & 3.35 & 1.06 & 0.32 \\ \text { F49 } & 3.35 & 1.21 & 0.36 \\ & & & \\ \text { F47 } & 3.33 & 1.00 & 0.30 \\ \text { C23 } & 3.32 & 0.95 & 0.29 \\ & 3.32 & & \\ \text { C27 } & 3.29 & 0.95 & 0.29 \\ \text { A7 } & 3.28 & 0.98 & 0.30 \\ \text { G60 } & 3.28 & 1.18 & 0.36 \\ \text { F50 } & 3.27 & 0.94 & 0.29 \\ \text { G53 } & 3.27 & 1.17 & 0.36 \\ \text { B13 } & 3.25 & 1.06 & 0.33 \\ \text { G58 } & 3.25 & 1.06 & 0.33 \\ \text { B12 } & 3.21 & 1.12 & 0.35 \\ \text { A9 } & 3.20 & 1.20 & 0.38 \\ \text { B15 } & 3.19 & 1.11 & 0.35 \\ \text { C24 } & 3.19 & 1.00 & 0.31 \\ \text { D32 } & 3.19 & 1.05 & 0.33 \\ \text { H61 } & 3.19 & 1.07 & 0.34 \\ \text { C21 } & 3.17 & 1.10 & 0.35 \\ & & & (\text { continued }) \\ & & & \end{array}$


Cluster Measure

Employee turnover

Percent of products rejected by the quality control

Percent of sales from proprietary products

4

Product development time

Manufacturing cycle time

Litigation with the community

Number of new patents (last three years)

Litigation with customers

Earnings per share

Order to delivery time

Community involvement

Warranty claims

Percent of downtime on the production

Insurance plans (life, health and education)

Litigation due to break of market competition rules

Safety record

5

Note: Clusters were predefined to five to provide an analogy with the scale used on the questionnaire

$\mathrm{C} 17 \quad 3.15$

E41 2.82
1.12

0.97

1.06

1.12

1.13

1.07

1.07

1.16

1.07

1.08

1.14

0.98

1.03

1.05

0.97

1.11
Standard Coefficient

An examination Cat. Average deviation of variation of manufacturing

G57 $\quad 3.17$

1.16

E39 3.14

C18 3.11

C19 3.09

H63 3.09

D33 3.08

B16 3.05

A1 $\quad 3.00$

C20 3.00

H62 2.97

B11 2.96

C29 2.94

G56 2.86

G59 2.81

G52 2.47
0.37

0.36

0.31

0.34

0.36

0.37

0.35

0.35

0.39

0.36

0.36

0.39

0.33

0.36

0.37

0.35

0.45

\section{organizations}

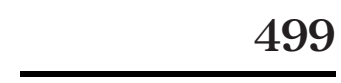

499

financial measures. The measures with the highest PV, in the first two clusters, appear to be uniformly distributed in terms of their categories (i.e. A(4), C(4), D(3), E(6), F(3) and $\mathrm{G}(4)$ ). The absence of measures related to category $B$ (product quality and customer satisfaction) and category $\mathrm{H}$ (social responsibility) is noted. The absence of category $\mathrm{H}$ measures is understandable, since issues related to social responsibility are just beginning to gain importance in Portugal.

The fact that measures from category B appear to be among the measures least used (Table II), as well as considered not to have high PV (Table III) is rather interesting. Also, it is interesting to note that while measures of the financial category are not viewed to have very high PV, nevertheless these measures are among the most used in the evaluation of organizational performance.

The cluster analysis results related to the ease of acquisition of information of the studied measures are presented in Table IV. As expected, the first cluster includes eight traditional measures from the financial category, and just one measure from the non-financial categories. The ninth measure of the financial category which represents the quality of accounting policies is in the fourth cluster. Out the 17 measures, 9 measures with the highest value in terms of the ease of acquisition are non-financial in nature. These measures are from categories $\mathrm{C}, \mathrm{E}$ and $\mathrm{F}$. It is interesting to note that six of the seven measures of category B (product quality and customer satisfaction) are in the tail end of Table IV. These measures appear to be considered by the financial analysts as among the measures which are the most difficult to acquire information for. Based on the results in Tables II-IV, measures of category B appear to be the least used, perceived to have little PVs, and considered the most difficult to get information for.

Table $\mathrm{V}$ presents the average of responses for each category, as well as the ranking of these values for the three variables (FU, PV and EA). Based on the results in Table V, 
IJOPM

24,5

\section{0}

2

3

Table IV.

Cluster analysis results relative to the ease of information acquisition measure
Cluster Measure

Standard Coefficient

Cat. Average deviation of variation

1 Sales

Return on equity

Cash flow

Equity $\div$ total assets

Earnings per share

Sales $\div$ total assets

Return on assets

EEBIT \& EI $\div$ sales

Accounts receivable $\div$ sales

Sales per employee

Cost of goods sold $\div$ inventory

Dispersion of ownership

Operating costs per employee

Continuity of management

Product diversification

Geographic diversification

Customer diversification

3 Experience/reputation of management

Market share

Age of plant and equipment

Brand awareness

Participation of shareholders on the firm's

management

Employee training

Number of new products (last three years)

Percent of sales from proprietary products

Manufacturing cycle time

Strategic alliances

$\mathrm{R} \& \mathrm{D}$ expenditures

Profit share or other incentive plans

Future investment needs

Capacity utilization

4 Independence of the management relative to the shareholders

Median

Percent of sales due to new products

Quality of accounting policies

Number of new patents (last three years)

Employee turnover

Potential for new competitors

Abentee rates

Order to delivery time

Insurance plans (life, health and education)

Percent of products protected by patents

Environmental policies implemented

Actual production $\div$ planned production

Safety record

$\begin{array}{llll}\text { A5 } & 4.63 & 0.69 & 0.15 \\ \text { A3 } & 4.44 & 0.85 & 0.19 \\ \text { A2 } & 4.42 & 0.88 & 0.20 \\ \text { A8 } & 4.39 & 0.85 & 0.19 \\ \text { A1 } & 4.36 & 0.90 & 0.21 \\ \text { A7 } & 4.36 & 0.88 & 0.20 \\ \text { A4 } & 4.29 & 0.93 & 0.22 \\ \text { A6 } & 4.19 & 0.87 & 0.21 \\ \text { C25 } & 4.08 & 1.00 & 0.25 \\ \text { C23 } & 3.86 & 1.03 & 0.27 \\ \text { C24 } & 3.74 & 1.14 & 0.30 \\ \text { F50 } & 3.70 & 0.99 & 0.27 \\ \text { C22 } & 3.58 & 1.03 & 0.29 \\ \text { F45 } & 3.55 & 1.16 & 0.33 \\ \text { E44 } & 3.51 & 0.96 & 0.27 \\ \text { E42 } & 3.45 & 1.03 & 0.30 \\ \text { E43 } & 3.41 & 0.99 & 0.29 \\ \text { F46 } & 3.30 & 1.15 & 0.35 \\ \text { E36 } & 3.29 & 1.01 & 0.31 \\ \text { C28 } & 3.28 & 1.20 & 0.37 \\ \text { E37 } & 3.22 & 1.01 & 0.31 \\ & & & \\ \text { F47 } & 3.16 & 1.18 & 0.37 \\ \text { G54 } & 3.16 & 1.03 & 0.33 \\ \text { D34 } & 3.13 & 1.16 & 0.37 \\ \text { E39 } & 3.13 & 1.11 & 0.35 \\ \text { C19 } & 3.09 & 1.10 & 0.36 \\ \text { E40 } & 3.06 & 1.18 & 0.39 \\ \text { D31 } & 3.03 & 1.06 & 0.35 \\ \text { G55 } & 3.03 & 1.08 & 0.36 \\ \text { C26 } & 3.01 & 1.08 & 0.36 \\ \text { C30 } & 3.01 & 0.92 & 0.31 \\ & & & \\ \text { F48 } & 2.96 & 1.27 & 0.43 \\ & 2.96 & & \\ \text { D35 } & 2.95 & 1.13 & 0.38 \\ \text { A9 } & 2.88 & 1.09 & 0.38 \\ \text { D33 } & 2.82 & 1.17 & 0.41 \\ \text { G57 } & 2.81 & 1.18 & 0.42 \\ \text { E38 } & 2.80 & 1.13 & 0.40 \\ \text { G58 } & 2.78 & 1.21 & 0.44 \\ \text { C20 } & 2.76 & 1.19 & 0.43 \\ \text { G56 } & 2.76 & 1.08 & 0.39 \\ \text { D32 } & 2.75 & 1.15 & 0.42 \\ \text { H61 } & 2.67 & 0.92 & 0.34 \\ \text { C27 } & 2.64 & 1.23 & 0.47 \\ \text { G59 } & 2.59 & 1.25 & 0.48 \\ & & & (07 t 3\end{array}$

(continued) 
Cluster Measure

\section{Stan}

Standard

Cat. Average

Litigation with the community
Community involvement
Percent of products rejected by
Employee involvement
Product development time
Ability to customize products
Litigation due to break of market
Ethical behavior of management
Percent of downtime on the prod
Shareholder disputes
Litigation with customers
Labor-management relations
Equal employment opportunity
Percent of returned orders
Percent of missed delay dates
Warranty claims
Customer surveys
Customer complaints
Service responsiveness

H63

H62

C17

G53

C18

C21

E41

F51

C29

F49

B16

G60

G52

B15

B13

B11

B10

B12

B1

2.57
2.54
2.53
2.53
2.50
2.48
2.45
2.41
2.38
2.37
2.36
2.34
2.27
2.25
2.18
2.17
2.14
2.14
2.10

1.06

1.08

1.26

1.08

1.06

1.03

1.16

1.19

1.06

1.08

1.12

1.06

1.12

1.20

1.13

1.09

1.06

1.08

1.05

An examination of manufacturing

0.41

0.43

0.50

0.43

0.42

0.42

0.47

0.49

0.45

0.46

0.47

0.45

0.49

0.53

0.52

0.50

0.50

0.50

0.50 organizations

501

Note: Clusters were predefined to five to provide an analogy with the scale used on the questionnaire

Table IV.

\begin{tabular}{|c|c|c|c|c|c|c|c|}
\hline \multirow[b]{2}{*}{ Category } & \multirow[b]{2}{*}{$\mathrm{FU}$} & \multirow[b]{2}{*}{ Rank } & \multicolumn{2}{|c|}{ Mean } & \multirow[b]{2}{*}{ EA } & \multirow[b]{2}{*}{ Rank } & \\
\hline & & & PV & Rank & & & \\
\hline A. Financial & 4.03 & 1 & 3.51 & 2 & 4.22 & 1 & \\
\hline E. Competitive environment & 3.63 & 2 & 3.59 & 1 & 3.15 & 2 & \\
\hline F. Quality/independence of management & 3.58 & 3 & 3.51 & 2 & 3.06 & 4 & \\
\hline C. Process efficiency & 3.16 & 4 & 3.32 & 5 & 3.07 & 3 & \\
\hline D. Product and process innovation & 3.01 & 5 & 3.40 & 4 & 2.94 & 5 & \\
\hline G. Human resource management & 2.91 & 6 & 3.16 & 7 & 2.70 & 6 & Table V. \\
\hline H. Social responsibility & 2.79 & 7 & 3.08 & 8 & 2.59 & 7 & Ranking of performance \\
\hline B. Product quality and customer satisfaction & 2.39 & 8 & 3.20 & 6 & 2.19 & 8 & measure categories \\
\hline
\end{tabular}

measures of the financial category are found in first place both in terms of the FU and the EA variables. This finding is not surprising. The frequent use of financial measures in the evaluation of performance of manufacturing organizations may be attributed to the fact that information on these measures is the most readily available. In addition, these measures are ranked second with respect to the PV variable. Thus, the frequent use of these measures may also be attributed to the fact that financial analysts perceive these measures as having high PVs. Among the non-financial categories, the competitive environment (E) and quality/independence of management (F) categories appear to be the highest in rank. On the other hand, product quality and customer satisfaction (B) appear to be the lowest in rank, thus confirming the results presented earlier. 
IJOPM

24,5

502
Regression analysis results

Based on the results shown in Table I, almost half of the financial analysts surveyed in this study work in banks or other financial institutions. The question here is whether those financial analysts who work in financial institutions tends to differ from those who do not in relation to variables and measures studied. We tested the following model to address this question:

$$
\overline{\mathrm{FU}_{i}}=\alpha_{0}+\alpha_{1} \overline{\mathrm{PV}_{i}}+\alpha_{2} \overline{\mathrm{EA}_{\mathrm{i}}}+\alpha_{3} \mathrm{CT}_{i}+e_{i}
$$

In this model, which was defined in the methodology section earlier, $\mathrm{CT}_{i}$ is the binary variable which assumes the value 1 , if the analyst works in a bank or a financial institution, and 0 in the remaining cases. The regression results related to testing this model are presented in Table VI.

Based on the results in Table VI, the $R^{2}$ value indicates that the model explained 87.3 percent of the behavior of the dependent variable. However, the coefficient of the variable CT is not statistically significant ( $\alpha=0.05$ ). Therefore, it is concluded that no significant differences exist between the analysts who work in banks and financial institution and those who do not with respect to the utilization of performance measures studied. This is not surprising, since financial analysts receive similar training and education, and also the Portuguese financial market is relatively small and concentrated.

Based on these results, the model proposed initially appears to be sufficient. Thus, the linear function to be estimated is:

$$
\overline{\mathrm{FU}_{i}}=\alpha_{0}+\alpha_{1} \overline{\mathrm{PV}_{i}}+\alpha_{2} \overline{\mathrm{EA}_{i}}+e_{i}
$$

The observation unit used in this model is the average of the responses of the analysts surveyed for each measure. After verifying the assumptions relevant for linear regression, a stepwise procedure to select variables to include in the model was used. This procedure resulted in the inclusion of the two independent variables.

The regression results shown in Table VII indicate a high $R^{2}$ of 89.7 percent revealing that almost 90 percent of the total variability in the FU measures has been explained by the PV and the ease of acquisition measures. The estimated regression coefficients were found to be significant ( $\alpha=0.05)$.

Since we are analyzing a behavior profile, it is important to evaluate the deviations from that profile. In this context, it is important to evaluate the measures used in this study to assess which of them depart from the profile. To accomplish this, the

\begin{tabular}{|c|c|c|c|c|c|}
\hline & $\begin{array}{c}\text { Unstandard } \\
\text { coefficients } \\
B\end{array}$ & Std. error & $\begin{array}{c}\text { Standardized } \\
\text { coefficients } \\
\beta\end{array}$ & $t$ & Sig. \\
\hline (Constant) & -1.404 & 0.199 & - & -7.046 & 0.000 \\
\hline PV & 0.888 & 0.065 & 0.492 & 13.594 & 0.000 \\
\hline EA & 0.551 & 0.033 & 0.599 & 16.576 & 0.000 \\
\hline CT & -0.065 & 0.041 & -0.052 & -1.598 & 0.113 \\
\hline
\end{tabular}
regression model below is used:

Note: $R=0.934 ; R^{2}=0.873$; Adjusted $R^{2}=0.870$; Std. error of the estimate $=0.229$
Table VI.

Regression results based on the type of organization 


$$
\mathrm{FU}=-1.414+0.878 \mathrm{PV}+0.588 \mathrm{EA}
$$

Table VIII reveals a set of measures with positive signs which represents the measures most used, and a set of measures with negative signs representing the least used measures. Within the group of measures most used, quality of accounting policies and the ethical behavior of management stand out as the two measures with values higher than all others. Perhaps this finding has to do with the fact that these two measures have been receiving increased attention in Portugal in recent years. This group of nine measures, included four measures related to the quality/independence of management category, two measures related to competitive environment, while the remaining three measures were from the financial, process efficiency and human resource management categories respectively. On the other hand, within the least used measures group, four measures from the product quality and customer satisfaction category, one from the process efficiency, and one from the product and process innovation categories are found.

\begin{tabular}{|c|c|c|c|c|c|c|c|}
\hline & \multirow{2}{*}{$\begin{array}{c}\text { Unstandard } \\
\text { coefficients } \\
\text { B }\end{array}$} & \multicolumn{3}{|c|}{$\begin{array}{l}\text { Standardized } \\
\text { coefficients }\end{array}$} & & \multicolumn{2}{|c|}{$\begin{array}{l}95 \text { percent confidence } \\
\text { interval for } B\end{array}$} \\
\hline & & $\begin{array}{l}\text { Std. } \\
\text { error }\end{array}$ & $\beta$ & $t$ & Sig. & $\begin{array}{l}\text { Lower } \\
\text { bound }\end{array}$ & $\begin{array}{l}\text { Upper } \\
\text { bound }\end{array}$ \\
\hline (Constant) & -1.414 & 0.255 & --- & -5.544 & 0.000 & -1.924 & -0.904 \\
\hline PV & 0.878 & 0.085 & 0.483 & 10.304 & 0.000 & 0.707 & 1.048 \\
\hline EA & 0.558 & 0.042 & 0.621 & 13.245 & 0.000 & 0.474 & 0.642 \\
\hline
\end{tabular}

Note: $R=0.947 ; R^{2}=0.897 ;$ Adjusted $R^{2}=0.893$; Std. error of the estimate $=0.2007$
An examination of manufacturing organizations

503

Table VII.

Regression results
Measure

Significant positive residuals (more use)

Quality of accounting policies

Ethical behavior of management

Shareholder disputes

Equal employment opportunity

Market share

Future investment needs

Litigation due to break of market competition rules

Participation of shareholders on the firm's management

Independence of the management relative to the shareholders

Significant negative residuals (less use)

Customer surveys

Number of new patents (last three years)

Percent of missed delay dates

Customer complaints

Operating costs per employee

Percent of returned orders

Note: Measures with significant standardized residuals $(\alpha=0.1)$
Standardized

Category residual

$\begin{array}{rr}\text { A9 } & 2.438 \\ \text { F51 } & 2.384 \\ \text { F49 } & 1.556 \\ \text { G52 } & 1.297 \\ \text { E36 } & 1.289 \\ \text { C26 } & 1.276 \\ \text { E41 } & 1.259 \\ \text { F47 } & 1.192 \\ \text { F48 } & 1.135 \\ & \\ \text { B10 } & -2.314 \\ \text { D33 } & -1.902 \\ \text { B13 } & -1.515 \\ \text { B12 } & -1.478 \\ \text { C22 } & -1.378 \\ \text { B15 } & -1.297\end{array}$

Table VIII.

Departure of residual errors from the estimated profile 
IJOPM

24,5

504

Following the methodology proposed earlier, the relative use of the categories of information is evaluated using the following model:

$$
\overline{\mathrm{FUc}_{i}}=\beta_{0}+\beta_{1} \overline{\mathrm{VPc}_{i}}+\beta_{2} \overline{\mathrm{FAc}_{i}}+\sum_{j=1}^{7} \gamma_{j} D_{j}+\sum_{j=1}^{7} \delta_{j} D_{j} \overline{\mathrm{VPc}_{i}}+\sum_{j=1}^{7} \lambda_{j} D_{j} \overline{\mathrm{FAc}_{i}}+\mu_{i}
$$

In this model, the observation unit is the average of all measures of each category for all analysts surveyed, thus resulting in a maximum of $632(79 \times 8)$ observations. This number, however, was reduced to 627 , due to incomplete instruments.

The regression results shown in Table IX revealed that the estimated coefficients for variables PV and EA maintained their positive signs. On the other hand, only two of the seven binary variables representing the information categories were selected by the stepwise regression procedure, namely D2 - process efficiency and D6 - human resources management Only two interaction terms with the PV variable and two with the ease of acquisition variable were selected by this stepwise procedure. For better understanding, we replaced the numeric indexes of the binary variables by the letters corresponding to the categories used, resulting in the following model:

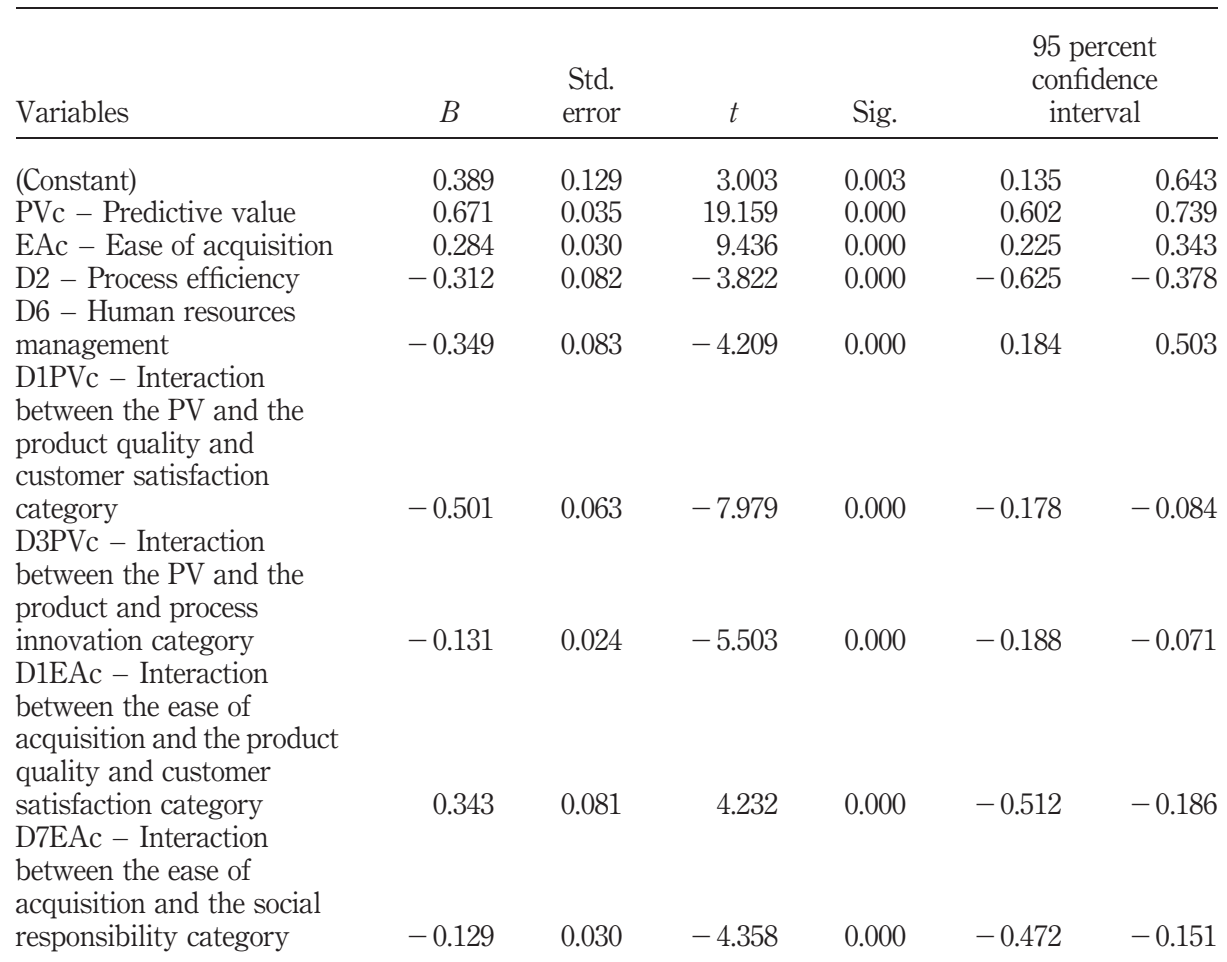

Table IX.

Regression results
Note: $R=0.777 ; R^{2}=0.604 ;$ Adjusted $R^{2}=0.599 ;$ Std. of the error estimate $=0.6306$ 


$$
\begin{aligned}
\mathrm{FUc} & =0.389+0.671 \mathrm{PV} \mathrm{c}+0.284 \mathrm{EAc}-0.312 D_{\mathrm{C}}-0.349 D_{\mathrm{G}} \\
- & 0.501 D_{\mathrm{B}} \mathrm{PV} \mathrm{c}-0.131 D_{\mathrm{D}} \mathrm{PV} \mathrm{c}+0.343 D_{\mathrm{B}} \mathrm{EAc}-0.129 D_{\mathrm{H}} \mathrm{EAc}
\end{aligned}
$$

An examination of the binary variables which represent the information categories shows that both have negative signs. As mentioned earlier, in the methodology section, these coefficients indicate the deviations in the intercept term from the financial category. If we just consider the selected information categories, we will have:

$$
D_{\mathrm{B}}=0 ; \quad D_{\mathrm{D}}=0 ; \quad D_{\mathrm{H}}=0 ;
$$

Thus, we can analyse the categories $\mathrm{C}$ and $\mathrm{G}$, relative to the financial category based on:

$$
\mathrm{FUc}=0.389+0.671 \mathrm{PV} \mathrm{c}+0.284 \mathrm{EAc}-0.312 D_{\mathrm{C}}-0.349 D_{\mathrm{G}}
$$

Therefore, in the context of this last model, if $D_{\mathrm{C}}=0$ and $D_{\mathrm{G}}=0$, we have the relationship representative of the financial information category:

$$
\mathrm{FUc}=0.389+0.671 \mathrm{PV} \mathrm{c}+0.284 \mathrm{EAc}
$$

On the other hand, if $D_{\mathrm{C}}=1$ and $D_{\mathrm{G}}=0$, we have the relationship representative of the category $\mathrm{C}$ (process efficiency):

$$
\mathrm{FUc}=0.077+0.671 \mathrm{PV} \mathrm{c}+0.284 \mathrm{EAc}
$$

Finally, if $D_{\mathrm{C}}=0$ and $D_{\mathrm{G}}=1$, we have the relationship representative of the category $\mathrm{G}$ (human resources management):

$$
\mathrm{FUc}=0.040+0.671 \mathrm{PV} \mathrm{c}+0.284 \mathrm{EAc}
$$

Thus, we can conclude that for both categories there exists a decrease in the intercept coefficient $(0.04<0.077<0.389)$ due to the negative coefficients of the binary variables relative to the non-financial categories in the analysis. We conclude that the financial analysts assigned negative weights to these information categories, relative to the financial category. Owing to the negative signs of the statistically significant coefficients, we can affirm that for the same PV and for the same ease of acquisition, the financial analysts tend to use the measures of these two categories less frequently, relative to the measures of the financial category. With regard to the remaining non-financial categories, although not included in this model, they are all presented by negative sign. The above findings are consistent with the results reported by Dempsey et al. (1997). Based on these findings, we can conclude that we have three possible scenarios:

(1) The financial analysts tend to use, in an irrational way, too much financial information.

(2) The financial analysts tend to also use, in an irrational way, very little non-financial information.

(3) Our model is not fully specified, that is, the FU is not only a linear function of the PV and of the ease of acquisition. 
IJOPM

24,5

506
To examine the results related to the interaction terms which show the changes in the coefficients of PV and EA when the category of information is non-financial, we used a similar approach to analyse the relationship of the category D to the PV. The PV coefficient decreased relatively in comparison to the financial category model due to the negative sign of the interaction term coefficient. We can, therefore, conclude that for an increase of the $P V$ of the measures of this category, there will be a smaller FU in comparison to the measures of the financial category. Thus, the FU of the category D measures is less sensitive to the increase in the PV, when compared to the measures of the financial category. It is to be recalled that when the variables were analyzed individually (Table IV), it was determined that in terms of ease of acquisition, the measures of the category D were found in the third and fourth clusters, thus confirming the lack of sensitivity of this category to the PV due to a high acquisition cost.

Analyzing the interaction between the measures of the category $\mathrm{H}$ and the ease of acquisition, it is observed that ease of acquisition coefficient decreased in comparison to the financial category model due to the negative sign of the interaction term coefficient. This is interpreted to mean that relative to the financial information model, the less this type of information is used, the easier it is to acquire. This interpretation is meaningless. However, it perhaps suggest that analysts may be somewhat suspicious of the integrity of this type of information as firms sometimes disclose such information only for the purpose of gaining favorable public opinion (Dempsey et al., 1997).

Finally, the interactions between the measures of the category B, and the ease of acquisition and PV variables were analyzed. The ease of acquisition coefficient increased, while simultaneously the PV coefficient decreased in comparison to the financial category model due to the signs of both interaction term coefficients. Therefore, it appears that FU of measures of this category is much more sensitive to ease of information acquisition than in relation to the PV. It is to be recalled that based on the results in Table IV for ease of acquisition variable, the seven measures of the category B were found to be at the tail of the last cluster. This perhaps confirms the lack of sensitivity of this category to the PV, especially in light of a prohibitive cost of information acquisition.

\section{Gap analysis results}

To understand the reasons behind the apparent lack of relative use of the non-financial measures on the part of the financial analysts, the relationships among the PV and the ease of information acquisition scores for each of the 63 measures were examined using the indicator (GAP) equation below:

$$
\mathrm{GAP}_{i}=\left(\mathrm{PV}_{i}-\mathrm{EA}_{i}\right) \mathrm{PV}_{i}
$$

As mentioned earlier, in the methodology section, the larger is this indicator (GAP) the greater will be the disparity between the usefulness of the measure and its availability for the analysts. Negative or relatively small values for this indicator indicate a surfeit of information. Thus, the measures studied were divided into two groups. The first group includes those measures with negative indicator (Table X). For these measures, it appears confirmed that information exists in excess, since such information can be 


\begin{tabular}{|c|c|c|c|c|c|c|}
\hline Rank & Measure & Cat & PV & EA & Gap & n examination \\
\hline 50 & Geographic diversification & $\mathrm{E} 42$ & 3.39 & 3.45 & -0.20 & ors \\
\hline 51 & Operating costs per employee & $\mathrm{C} 22$ & 3.40 & 3.58 & -0.61 & 018 \\
\hline 52 & EBIT\&EI $\div$ sales & A6 & 3.97 & 4.19 & -0.87 & \\
\hline 53 & Dispersion of ownership & F50 & 3.27 & 3.70 & -1.41 & \\
\hline 54 & Cash flow & A2 & 4.00 & 4.42 & -1.68 & $\mathbf{n}^{\prime}$ \\
\hline 55 & Cost of goods sold $\div$ inventory & $\mathrm{C} 24$ & 3.19 & 3.74 & -1.75 & \\
\hline 56 & Sales per employee & $\mathrm{C} 23$ & 3.32 & 3.86 & -1.79 & \\
\hline 57 & Accounts receivable $\div$ sales & $\mathrm{C} 25$ & 3.57 & 4.08 & -1.82 & \\
\hline 58 & Return on equity & A3 & 3.66 & 4.44 & -2.85 & \\
\hline 59 & Return on assets & A4 & 3.42 & 4.29 & -2.98 & \\
\hline 60 & Sales & A5 & 3.71 & 4.63 & -3.41 & \\
\hline 61 & Equity $\div$ total assets & A8 & 3.35 & 4.39 & -3.48 & Table Y \\
\hline 62 & Sales $\div$ total assets & A7 & 3.28 & 4.36 & -3.54 & Measures with a negati \\
\hline 63 & Earnings per share & A1 & 3.00 & 4.36 & -4.08 & gap indicator \\
\hline
\end{tabular}

extracted from the organizational documents regularly maintained by the manufacturing companies.

The second group includes those measures with GAP values above the average (1.96) of all positive GAP values. Table XI shows the measures with the largest disparity between their usefulness and their information availability, thus reflecting the lowest availability of valuable information. Among those measures, seven measures from category B (product quality and customer satisfaction) are found. It is to be kept in mind that category B was found to be the category with lowest values for

\begin{tabular}{|c|c|c|c|c|c|c|}
\hline Ord & Measure & Cat & $\mathrm{PV}$ & EA & Gap & \\
\hline 1 & Customer surveys & $\mathrm{B} 10$ & 3.39 & 2.14 & 4.24 & \\
\hline 2 & Service responsiveness & B14 & 3.36 & 2.10 & 4.23 & \\
\hline 3 & Future investment needs & $\mathrm{C} 26$ & 4.01 & 3.01 & 4.01 & \\
\hline 4 & Potential for new competitors & E38 & 3.84 & 2.80 & 3.99 & \\
\hline 5 & Percent of missed delay dates & B13 & 3.25 & 2.18 & 3.48 & \\
\hline 6 & Ethical behavior of management & F51 & 3.42 & 2.41 & 3.45 & \\
\hline 7 & Customer complaints & B12 & 3.21 & 2.14 & 3.43 & \\
\hline 8 & Shareholder disputes & F49 & 3.35 & 2.37 & 3.28 & \\
\hline 9 & Labor-management relations & G60 & 3.28 & 2.34 & 3.08 & \\
\hline 10 & Percent of returned orders & B15 & 3.19 & 2.25 & 3.00 & \\
\hline 11 & Market share & E36 & 4.00 & 3.29 & 2.84 & \\
\hline 12 & Percent of sales due to new products & D35 & 3.70 & 2.95 & 2.78 & \\
\hline 13 & Brand awareness & E37 & 3.91 & 3.22 & 2.70 & \\
\hline 14 & Employee training & G54 & 3.84 & 3.16 & 2.61 & \\
\hline 15 & Experience/reputation of management & F46 & 3.95 & 3.30 & 2.57 & \\
\hline 16 & Employee involvement & G53 & 3.27 & 2.53 & 2.42 & \\
\hline 17 & Warranty claims & B11 & 2.96 & 2.17 & 2.34 & \\
\hline 18 & Capacity utilization & C30 & 3.62 & 3.01 & 2.21 & \\
\hline 19 & Ability to customize products & $\mathrm{C} 21$ & 3.17 & 2.48 & 2.19 & Table XI. \\
\hline 20 & Actual production $\div$ planned production & $\mathrm{C} 27$ & 3.29 & 2.64 & 2.14 & Measures with gap \\
\hline 21 & Litigation with customers & $\mathrm{B} 16$ & 3.05 & 2.36 & 2.10 & indicators above average \\
\hline 22 & Strategic alliances & E40 & 3.63 & 3.06 & 2.07 & of the positive values \\
\hline
\end{tabular}


IJOPM 24,5

508 the ease of acquisition and FU variables (Table V). Thus, confirming that the infrequent use of category B measures is not due to an irrational behavior on the part of the financial analysts, rather it is due to the high cost of acquiring such information.

\section{Conclusion}

Recent literature related to manufacturing performance measurement points to the increasing relevance of non-financial measures in the evaluation of manufacturing organizational performance (Mavrinac and Siesfeld, 1998). However, results obtained by Dempsey et al. (1997) suggest that, while financial analysts utilize and even value non-financial measures, manufacturing organizations either do not have or are not willing to share information relevant to these measures. It is with that in mind that this study is carried out.

The objective of this investigation is to examine the role and nature of financial versus non-financial measures in the context of information availability on these measures, their extent of utilization and their perceived relevance. Specifically, the extent of use, importance and availability of information for a group of 63 financial and non-financial measures, as seen by 79 financial analysts who evaluate the performance of manufacturing organizations are examined. The results of this study derived from cluster analysis and multiple regression analyses point to some important conclusions which have both practical and future research implications.

The cluster analysis results for the extent of use of the different measures studied appear to indicate that both financial and non-financial measures are utilized by the financial analyses in their performance evaluation process. Thus, it seems that financial analysts tend to broadly view manufacturing performance. In this context, they are not limiting their evaluation of the well-being of the evaluated organizations to traditional financial measures only. Therefore, management of manufacturing organizations should also utilize the non-financial measures, when evaluating internal performance. If such measures are not readily available from traditional PMSs, then these systems should be re-engineered to ensure the systematic tracking and documentation of non-financial performance measures.

The results of the cluster analysis in relation to the importance (PV) of the measures studied are perhaps the most interesting. These results appear to indicate that the analysts favor non-financial measures. In this context, the financial analysts perceive the non-financial measures as having more importance to predicting the overall well-being of the evaluated organizations. This perhaps is another reason for the management of manufacturing organizations to re-examine the organizational PMSs in order to emphasis such measures. Such effort should be guided by the effective utilization of the non-financial measures in organizational performance measurement.

The results of the cluster analysis in relation to the availability of information (ease of acquiring) on the measures studied are consistent with the results derived from the extent of use analysis. This is a logical finding, as analysts tend to use measures for which information is available. However, this is not to be interpreted to mean that the financial analysts may not demand information on measures which they deem to be important. In fact, the results of the gap analysis which examined the gaps between the PV and the availability of information for a particular measure tend to confirm this contention. In this context, the gap analysis results for non-financial measures, in 
general, appear to be positive; thus indicating high PV and lack of information. On the other hand, for the most part, the opposite is true for most financial measures. This perhaps confirms the early conclusion stressing the need for management to redesign the organizational PMSs in order to emphasize the non-financial measures.

In general, the results appear to indicate that efficiency oriented measures are extensively utilized and that information on these measures appears to be readily available. However, the results also underscore the fact that non-financial measures such as quality, customer satisfaction and environmental measures are perceived to be important by the financial analysts, despite the apparent lack of information on these measures. Management of manufacturing organizations, therefore, should take this into consideration. In this context, the organizational PMS should be reoriented in order to not only make information on these important measures available, but also to promote their utilization in internal evaluation of organizational performance. In a customer-focused, quality-oriented, and natural environment-sensitive business marketplace, the tracking and utilization of measures related to the customer, product quality, and environmental impact should be viewed as a necessity rather a luxury in the context of a broader effectiveness oriented perspective on manufacturing performance.

Based on the relevant literature reviewed and the results of this study, a gap appears to exist between the practices of internal organizational decision makers (executives) and external decision makers (financial analysts) in relation to the relevance and utilization of performance measures, when evaluating the performance of manufacturing organizations. It appears that the unwillingness on the part of the executives to share certain performance related information with financial analysts is responsible for widening this gap. The framework in Figure 1 attempts to offer a conceptual context in which efforts aimed at narrowing this gap could be channeled. As such, this framework does not imply cause-and-effect relationships. The approach advocated in the framework is consistent with calls for practical research aimed at improving the art and theory of performance measurement and evaluation. In this context, research designed to narrow the informational gap between the internal and external decision makers is a step in the right direction

The framework underscores the need for consistency between internal and external utilization and perceived relevance of information generated by the PMS. When serious gaps, or even minor deviations exist between the internal and external perceptions, management of manufacturing organizations is called upon to undertake major initiatives or take corrective actions. In this context, for most managers, the temptation is always there to use and report traditional financial measures. However, the results of this study point to the fact that managers need to resist such temptation, as non-financial measures are being used and valued by those who evaluate their organizations. Thus, managers need to reorient their organizational cultures and processes not only to ensure the availability of information for non-financial measures, but also to promote the utilization of such information for internal performance evaluation purposes.

Organizational performance measurement in manufacturing settings is a dynamic process which never failed to challenge the creativity of practitioners, external evaluators as well as researchers. The results of this study and the research framework 
IJOPM

24,5

510

Figure 1.

Effective performance measurement: closing the gap between the external and internal perceptions

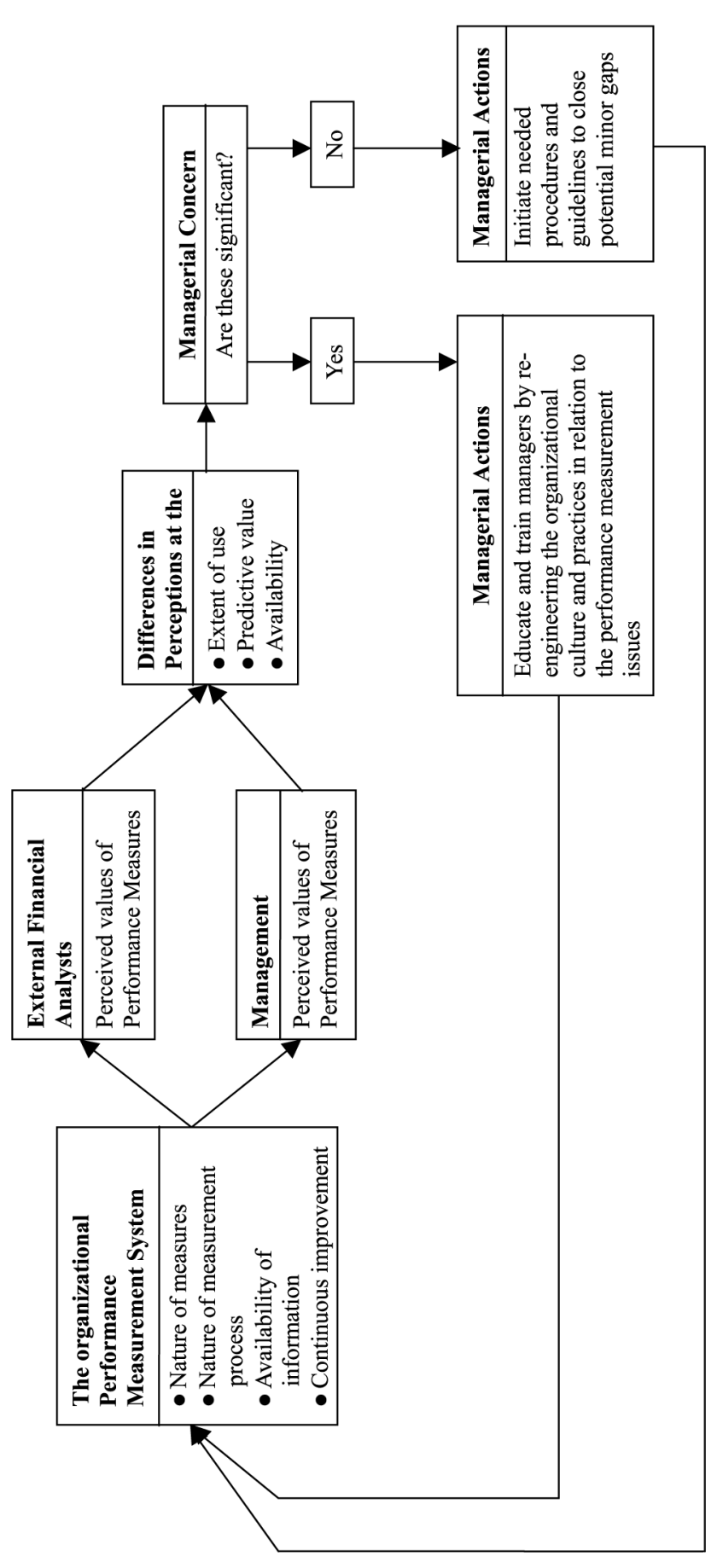


advanced for future research represent a small step in the direction of answering this difficult, yet worthy challenge.

\section{Notes}

1. For this reason, they are irrelevant in guiding managers in their quest to improve current and future operations (Clinton and Hsu, 1997).

2. EBIT\&EI - Earnings before interest, taxes and extraordinary items.

3. Devised from the literature.

\section{References}

Banker, R., Datar, S.M. and Kaplan, R.S. (1989), "Productivity measurement and management accounting", Journal of Accounting, Auditing \& Finance, Vol. 4 No. 4, p. 528.

Banks, R.I. and Wheelwright, S.C. (1979), "Operations versus strategy - trading tomorrow for today”, Harvard Business Review, May-June, pp. 112-20.

Beamon, B.M. (1999), "Measuring supply chain performance", International Journal of Operations \& Production Management, Vol. 19 No. 3, pp. 218-75.

Bhatt, G.D. (2000), "An empirical examination of the effects of information systems integration on business process improvement", International Journal of Operations \& Production Management, Vol. 20 No. 11, pp. 1331-59.

Bhimani, A. (1993), "Performance measures in UK manufacturing companies: the state of play", Management Accounting, Vol. 71 No. 11, pp. 20-2.

Birchard, B. (1995), "Making it count", CFO: The Magazine of Senior Financial Executives, Vol. 11 No. 10 , p. 42.

Carr, A.S., Leoong, G.K. and Sheu, C. (2000), "A study of purchasing practices in Taiwan”, International Journal of Operations \& Production Management, Vol. 20 No. 12, pp. 1427-45.

Clarke, P. (1995), "Non-financial measures of performance in management", Accountancy Ireland, Vol. 27 No. 2, pp. 22-4.

Clinton, D.B. and Hsu, K.-C. (1997), "JIT and the balanced scorecard: linking manufacturing control to management control”, Management Accounting, Vol. 79 No. 3, pp. 18-24.

Cross, K.F. and Lynch, R.L. (1988-1989), "The SMART way to define and sustain success", National Productivity Review, Vol. 9 No. 1, pp. 23-33.

De Toni, A. and Tonchia, S. (2001), "Performance measurement systems - models, characteristics and measures", International Journal of Operations \& Production Management, Vol. 21 No. 1/2, pp. 46-70.

Dempsey, S.J., Gatti, J.F., Grinnell, D.J. and Cats-Baril, W.L. (1997), "The use of strategic performance variables as leading indicators in financial analysts' forecasts", Journal of Financial Statement Analysis, Vol. 2 No. 4, pp. 61-79.

Dixon, J.R., Nanni, A.J. and Vollmann, T.E. (1990), The New Performance Challenge: Measuring Operations for World-class Competition, Business One Irwin, Homewood, IL.

Drucker, P.E. (1990), "The emerging theory of manufacturing", Harvard Business Review, May/June, pp. 94-102.

Eccles, R.G. (1991), “The performance measurement manifesto”, Harvard Business Review, January/February, pp. 617-35.

Eccles, R.G. and Pyburn, P.J. (1992), "Creating a comprehensive system to measure performancefinancial results should not generate the most rewards", Management Accounting, Vol. 74 No. 4, pp. 41-4.
An examination of manufacturing organizations 
IJOPM

24,5

512
Flapper, S.D.P., Fortuin, L. and Stoop, P.P.M. (1996), "Towards consistent performance management systems", International Journal of Operations \& Production Management, Vol. 16 No. 7, pp. 27-37.

Foster, G. and Gupta, M. (1994), "Marketing, cost management and management accounting", CAM-I, Arlington, TX.

Fry, T.D. and Cox, J.F. (1989), "Manufacturing performance: local versus global measures", Production and Inventory Management Journal, Vol. 30 No. 2, pp. 52-6.

Ghalayini, A.M., Noble, J.S. and Crowe, T.J. (1997), "An integrated dynamic performance measurement system for improving manufacturing competitiveness", International Journal of Production Economics, Vol. 48 No. 3, pp. 207-25.

Grady, M.W. (1991), "Performance measurement: implementing strategy", Management Accounting, Vol. 72 No. 12, pp. 49-53.

Green, F.B., Amenkhienan, F. and Johnson, G. (1991), "Performance measures and JIT", Management Accounting, Vol. 72 No. 8, pp. 50-3.

Hair, J.F. Jr, Anderson, R.E., Tatham, R.L. and Black, W.C. (1998), Multivariate Data Analysis, Prentice-Hall, Englewood Cliffs, NJ.

Hayes, R.H. and Garvin, D.A. (1982), "Managing as if tomorrow mattered", Harvard Business Review, May/June, pp. 70-9.

Hazell, M. and Morrow, M. (1992), "Performance measurement and benchmarking”, Management Accounting, December, pp. 44-5.

Hendricks, J.A. (1994), "Performances measures for a JIT manufacturer: the role of the IE", Industrial Engineering, Vol. 26 No. 1, pp. 26-9.

Johnson, H.T. and Kaplan, R.S. (1987), Relevance Lost - The Rise and Fall of Management Accounting, Harvard Business School Press, Boston, MA.

Kaplan, R.S. (1983), "Measuring manufacturing performance: a new challenge for managerial accounting research”, Accounting Review, Vol. 58 No. 4, pp. 686-703.

Kaplan, R.S. and Norton, D.P. (1992), "The balanced scorecard - measures that drive performance", Harvard Business Review, Vol. 70 No. 1, pp. 71-9.

Keegan, D.P., Eiler, R.G. and Jones, C.R. (1989), “Are your performance measures obsolete?”, Management Accounting, Vol. 71, June, pp. 45-50.

Khadem, R. (1988), "One page management: a unified approach to productivity", National Productivity Review, Vol. 8 No. 1, pp. 45-57.

Lynch, R.L. and Cross, K.F. (1991), Measure up - The Essential Guide to Measuring Business Performance, Mandarin, London.

McNair, C.J. and Mosconi, W. (1987), "Measuring performance in an advanced manufacturing environment", Management Accounting, Vol. 69 No. 1, pp. 28-31.

McNair, C.J., Lynch, R.L. and Cross, K.F. (1990), "Do financial and non-financial performance measures have to agree?", Management Accounting, Vol. 72 No. 5, pp. 28-36.

Manoochehri, G. (1999), "The road to manufacturing excellence: using performance measures to become world-class", Industrial Management, March-April, pp. 7-13.

Mavrinac, S. and Siesfeld, T. (1998), "Measures that matter: an exploratory investigation of investors' information needs and value priorities", Measuring Intangible Investment, Organization for Economic Co-operation and Development (OECD), Paris.

Medori, D. and Steeple, D. (2000), "A framework for auditing and enhancing performance measurement systems", International Journal of Operations \& Production Management, Vol. 20 No. 5, pp. 520-33. 
Najarian, G. (1993), "Performance measurement: measure the right things", Manufacturing Systems, September, pp. 54-7.

Najmi, M. and Kehoe, D.F. (2001), "The role of performance measurement systems in promoting quality development beyond ISO 9000", International Journal of Operations \& Production Management, Vol. 21 No. 1/2, pp. 159-72.

Neely, A.D., Mills, J.F., Gregory, M.J., Richards, A.H., Platts, K.W. and Bourn, M.C.S. (1996), Getting the Measure of Your Business, Findlay, London.

Noci, G. (1995), "Accounting and non-accounting measures of quality-based performances in of manufacturing organizations small firms”, International Journal of Operations \& Production Management, Vol. 15 No. 7 , pp. 78-105.

Santori, P.R. and Anderson, A.D. (1987), "Manufacturing performance in the 1990s: measuring for excellence", Journal of Accountancy, Vol. 164 No. 5, pp. 141-7.

Sohal, A.S., Moss, S. and Ng, L. (2001), "Comparing IT success in manufacturing and service industries", International Journal of Operations \& Production Management, Vol. 21 No. 1/2, pp. 30-45.

Tsang, A.H.C., Jardine, A.K.S. and Kolodny, H. (1999), "Measuring maintenance performance: a holistic approach", International Journal of Operations \& Production Management, Vol. 19 No. 7, pp. 691-715.

Upton, D. (1998), "Just-in-time and performance measures systems", International Journal of Operations \& Production Management, Vol. 18 No. 11, pp. 1101-11.

Wisner, J.D. and Fawcett, S.E. (1991), "Linking firm strategy to operating decisions through performance measurement”, Production \& Inventory Management Journal, Vol. 32 No. 3, pp. 5-11. 